\title{
Genome-Wide Identification and Expression Analysis of MIKC-Type MADS-Box Gene Family in Punica granatum L.
}

\author{
Yujie Zhao ${ }^{1,2}$, Honglian Zhao ${ }^{1,2}$, Yuying Wang ${ }^{1,2}$, Xinhui Zhang ${ }^{1,2}$, Xueqing Zhao ${ }^{1,2}$ and \\ Zhaohe Yuan 1,2,* \\ 1 Co-Innovation Center for Sustainable Forestry in Southern China, Nanjing Forestry University, \\ Nanjing 210037, China; z1184985369@njfu.edu.cn (Y.Z.); honglian_zhao@hotmail.com (H.Z.); \\ wangyuying@njfu.edu.cn (Y.W.); zhxinhui@hotmail.com (X.Z.); zhaoxq402@njfu.edu.cn (X.Z.) \\ 2 College of Forestry, Nanjing Forestry University, Nanjing 210037, China \\ * Correspondence: zhyuan88@hotmail.com
}

Received: 5 July 2020; Accepted: 10 August 2020; Published: 14 August 2020

\begin{abstract}
MADS-box is a critical transcription factor regulating the development of floral organs and plays essential roles in the growth and development of floral transformation, flower meristem determination, the development of male and female gametophytes, and fruit development. In this study, 36 MIKC-type MADS-box genes were identified in the 'Taishanhong' pomegranate genome. By utilizing phylogenetic analysis, 36 genes were divided into 14 subfamilies. Bioinformatics methods were used to analyze the gene structure, conserved motifs, cis-acting elements, and the protein interaction networks of the MIKC-type MADS-box family members in pomegranate, and their expressions pattern in different tissues of pomegranate were analyzed. Tissue-specific expression analysis revealed that the E-class genes (PgMADS03, PgMADS21, and PgMADS27) were highly expressed in floral tissues, while $P g M A D S 29$ was not expressed in all tissues, indicating that the functions of the E-class genes were differentiated. PgMADS15 of the C/D-class was the key gene in the development network of pomegranate flower organs, suggesting that PgMADS15 might play an essential role in the peel and inner seed coat development of pomegranate. The results in this study will provide a reference for the classification, cloning, and functional research of pomegranate MADS-box genes.
\end{abstract}

Keywords: Pomegranate; MIKC-type MADS-box genes; gene family identification; proteins interaction; expression analysis

\section{Introduction}

MADS-box (its name from Minichromosome maintenance 1 (MCM1), AGAMOUS (AG), DEFICIENS (DEF) and serum response factor (SRF)) genes encode transcription factors, have been widely found in plants, fungi, and animals, and contain the highly conservative MADS-domain composed of approximately 55 amino acids $[1,2]$. On the basis of genetic structures and phylogenetic analysis, the MADS-box family can be divided into two phylogenetically distinct groups: type I and type II [3]. Most of the well-studied plant genes are type II genes that have three more domains than those of type I genes: a more conservative intervening domain (I-domain), a moderately conservative keratin-like coiled-coil domain (K-domain), and a variable C-terminal domain (C-domain) [4]. These genes are considered as the MIKC-type and are specific to plants.

The plant-specific MIKC-type MADS-box genes were first identified as floral organ determinant genes in Arabidopsis thaliana and Antirrhinum majus [5,6]. MADS-box family genes are involved 
in plant growth and development, flower transformation, flower meristem decision, male/female gametophyte development, fruit development and maturation, and somatic embryogenesis [7-10]. Type I only contain MADS-domains without K-domains and are called M-type [11]. Type I genes are divided into four subfamilies: $\mathrm{M} \alpha, \mathrm{M} \beta, \mathrm{M} \gamma$, and $\mathrm{M} \delta$. Based on some research, the $\mathrm{M} \delta$ subfamily is referred to as type II, so it is also called MIKC*-type [12,13]. Type II genes can be divided into two subfamilies: MIKC* and MIKC ${ }^{C}$. MIKC $C^{C}$ subfamily can be divided into 13 branches: AG, AGL6 (AGAMOUS-LIKE, AGL), AGL12, AGL15, AGL17, AP1(APETALA, AP)/FUL (FRUITFULL), AP3/PI (PISTILLATA), FLC (FLOWERING LOCUS C), SOC1 (SUPPRESSOR OF OVEREXPRESSION OF CONSTANS1), SEP (SEPALLATA), SVP (SHORT VEGETATIVE PHASE), BS (B-SISTER), and TM8 [14,15]. In Arabidopsis, MIKC ${ }^{C}$-type embraces 12 subfamilies, without Tomato MADS 8 (TM8). So, there is little research on TM8's function [16].

According to the ABCDE model of flower development, the five class genes of A, B, C, D, and E coordinately regulate the development of sepals, petals, stamens, carpels, and ovules. Arabidopsis has two A-class genes (AP1 and AP2), two B-class genes (PI and AP3), C/D-class genes (AG, AGL11 and STK (SEEDSTICK)), and a single E-class gene (SEP), of which only AP2 is not a MADS-box gene [17]. The model suggests that $A+E$ control meristem and sepals' formation, $A+B+E$ regulates petals formation, $\mathrm{B}+\mathrm{C}+\mathrm{E}$ controls stamens formation, $\mathrm{C}+\mathrm{E}$ controls carpels formation, and C + D + E regulates ovules development [17]. Martín-Pizarro et al. identified two B-class genes FaAP3 and FaTM6 in strawberries (Fragaria $\times$ ananassa) and used CRISPR/Cas9 technology for the first time to study the function of FaTM6 in flower development. They found that FaTM6 played a key role in the development of strawberry petals and anthers; the expression pattern of FaTM6 was similar to AP3 in Arabidopsis [18]. AG is the first reported MADS-box gene to regulate stamens and carpels development [19]. C-class genes regulate the establishment of floral meristems by inhibiting the activity of the A-class gene [20]. In the control carpels, STK, SHP1, and SHP2 exist functional redundancy in some extent. SHP1, SHP2, and STK jointly regulate the development of ovules, with SHP1/SHP2 sharing some function of C- and D-class [21]. Ehlers et al. found that $\operatorname{sh} 1$ and $\operatorname{sh} 2$ could not coordinate the development of ovules, indicating that SHP1 and SHP2 might be the key genes regulating ovules development [22]. There are two AG subfamily genes TAG1 and TAGL1 in tomato. Pan et al. found that the stamens and carpel of TAGL1 RNAi strain were normal, and the fruit ripening was inhibited, speculating that TAGL1 shows new functions [23]. The development of stamens and carpel in TAG1 RNAi were significantly inhibited, indicating that TAG1 plays a major the role in regulating the development of stamens and carpel [23]. Xu et al. cloned three SEP-like genes, PrpMADS2, PrpMADS5, and PrpMADS7, in peach [24]. They found that the transgenic plant of PrpMADS2 had a similar phenotype with the wild. A strain with an overexpressed PrpMADS5 flowered earlier than the control plant, and it was involved in the differentiation of flower primordia. PrpMADS7 transgenic plants showed weak growth potential and earlier flowering than the wild, indicating new functions of the SEP-like gene [24]. SEP (SEPALLATA) participates in the formation of tetrameric protein complexes, and forms the complexes with A, B, and C-type proteins [25,26]. These complexes help to transform leaf primordia into floral organ primordium, of which ectopic expression of $\mathrm{A}, \mathrm{B}$, and $\mathrm{E}$ leads to the transformation of leaves into petals. The expression of $\mathrm{B}, \mathrm{C}$, and $\mathrm{E}$ gene causes the transformation of leaves into stamen organs [27].

Pomegranate (Punica granatum L.), belonging to Lythraceae family, is an excellent fruit tree with economic, nutritional, medicinal, ornamental, and ecological values [28]. Pomegranate is mostly cultivated in tropics and subtropics regions, such as the Mediterranean basin, Asia, Australia, and North America [29]. In China, the total scale of pomegranate cultivation is about $128,000 \mathrm{hm}^{2}$, with an annual output of about 1.7 million tons [28]. Pomegranate contains abundant polyphenols, tannins, anthocyanins, vitamins, and minerals, that are responsible to reduce blood pressure, and act against serious diseases such as cancer [30-32]. These have led to an increasing demand for the consumption of fresh fruit, juice, tea, and other pomegranate products. The completion genome sequencing of pomegranate and the publication of data [33-35] provided necessary data support for the promotion of 
research on gene function of pomegranate. In this study, we aim to identify the MIKC-type MADS-box members of pomegranate by bioinformatics methods, trying to analyze their gene structure, cis-acting elements, and tissue-specific expression to explore their functions in the development of pomegranate flowers. The results of this study would lay a foundation for the cloning and functional research of $P g M A D S$ genes.

\section{Materials and Methods}

\subsection{Data Collection for Expression Analysis}

The transcription data of pomegranate were obtained from the NCBI database (https://www.ncbi. nlm.nih.gov/), including leaves, roots, bisexual flowers, functional male flowers, exocarp, pericarp and other tissues. The respective accession sequence numbers are 'Dabenzi' SRR5678820, SRR5279388 SRR5279397; 'Baiyushizi' SRR5678819; 'Tunisian' SRR5446590 - SRR5446607; 'Black127' SRR1054190; 'Nana' SRR1055290; and 'Wonderful' SRR080723 (Table S1) [33,36-38].

MIKC-type MADS-box family protein sequences of Arabidopsis thaliana were downloaded from The Arabidopsis Information Source (https://www.arabidopsis.org/), and that of poplar (Populus trichocarpa) and apple (Malus domestica) were downloaded from Plant Transcription Factor Database (http://planttfdb.cbi.pku.edu.cn/index.php).

\subsection{Identification and Sequence Analysis of Pomegranate MIKC-Type MADS-Box Transcription Factors}

The HMM (Hidden Markov Models) profile of the Pfam MADS-domain (PF00319) was downloaded from the pfam database (http://pfam.xfam.org/). Then, the HMM profile was performed against pomegranate protein databases (GCA_002864125) using the HMMER 3.0 software package (The European Bionfirmatics Institute, Hinxton, Cambridgeshire, UK), $\left(\mathrm{E}-\mathrm{v}\right.$ alue $\left.<1 \mathrm{e}^{-5}\right)$, and redundant sequences were removed manually. Moreover, all obtained MADS protein sequences were further analyzed on the CDD website (https://www.ncbi.nlm.nih.gov/cdd) [39] to verify the presence of the MADS-domain. Identified MADS-box protein sequence were categorized using the PlantTFDB to follow-up analysis for M-type and MIKC-type MADS-box members [40,41].

The published MADS-box protein sequences of Arabidopsis, poplar and apple were used as queries to perform BLAST against the pomegranate protein database (E-value $<1 \mathrm{e}^{-10}$, identity $>50 \%$ ), duplication was removed. Having predicted and divided members into MIKC-type and M-type using the PlantTFDB website [40,41], MIKC-type MADS-box protein sequences were screened and selected.

ExPASy Proteomics Server (https://web.expasy.org/protparam/) was used to predict the physicochemical properties of MIKC-type MADS-box protein, including amino acid sequence length, molecular weight, and isoelectric point.

\subsection{Phylogenetic Analysis of Pomegranate MIKC-Type MADS-Box Family}

Multiple sequences alignment of pomegranate, Arabidopsis (45 members) and Poplar (51 members) MIKC-type MADS-box proteins were carried out using ClustalX 2.1 software (http://www.clustal.org/ omega/), and artificially corrected them. An unrooted neighbor-joining (NJ) phylogenetic tree was constructed with all of the MIKC-type MADS-box protein sequences from pomegranate, Arabidopsis, poplar using MEGA 7.0 (Penn State-A, State College, PA, USA) [42]. Bootstrap analysis was performed using 1000 repetitions with the following parameters: complete deletion and Poisson model. The phylogenetic tree was beautified with EvolView (https://www.evolgenius.info/evolview/\#login).

The subfamily was classified according to the support rate of subfamily branches $(>70)$ and the structural integrity of phylogenetic tree. Subfamily classification were obtained by according to Díaz-Riquelme et al. [15]. 


\subsection{Gene Structure Analysis and Motif Identification of Pomegranate MIKC-Type MADS-Box Family}

The protein sequences of the MIKC-type MADS-box were extracted from the pomegranate genome. Motifs of MIKC-type MADS-box proteins were identified using MEME online tools (http: //meme-suite.org/tools/meme) with a default parameter, and the motif characteristics of the MIKC-type MADS-box proteins were obtained. The SMART program (http://smart.embl.de/) was used to further analysis for the conservative motifs.

The annotation information of 36 MIKC-type MADS-box genes was extracted from the pomegranate genome annotation file, then the results were submitted to Gene Structure Display Server (GSDS 2.0: http://gsds.cbi.pku.edu.cn) for online genetic structure analysis and drawing Schematic diagram of gene structures.

\subsection{Prediction Promoter Elements and Protein Interaction Network of Pomegranate MIKC-Type MADS-Box Family}

To identify putative cis-acting elements in promoters, $1500 \mathrm{bp}$ upstream sequences of the initiation codon were obtained from the pomegranate genome sequence by TBtools (GitHub Inc., San Francisco, CA, USA) [43]. The cis-acting elements were analyzed by PlantCARE (http://bioinformatics.psb.ugent. be/webtools/plantcare/html/) [40]. Then, the result was presented as images using Tbtools.

The protein-protein interaction network of the MIKC-type MADS-box family was analyzed by String (https://string-db.org/).

\subsection{Expression Analysis for Pomegranate MIKC-Type MADS-Box Family}

To study the expression patterns of MIKC-type MADS-box genes in pomegranate different tissues, the published transcriptome data were downloaded as the primary data source for expression analysis from the NCBI database (http://www.ncbi.nlm.nih.gov/). Firstly, all RNA-Seq data were qualitatively controlled by fastp [44] to obtain cleaned reads. Then the sequences were indexed with pomegranate transcriptome data. Through the use of Kallisto 0.44 .0 software (https://pachterlab.github. io/kallisto/download.html) [45], and the gene expression levels was further calculated and analyzed. The corresponding expression level (TPM (Transcripts Per Million) value) of MIKC-type MADS-box genes was thus obtained. TPM value was transformed into $\log _{2}(T P M+1)$. Finally, the thermal map was drawn with Tbtools.

\section{Results}

\subsection{Identification and Sequence Analysis of Pomegranate MIKC-Type MADS-Box Family}

A total of 81 MADS-box family members were identified from the 'Taishanhong' pomegranate genome using the hmmsearch program. Through CDD online verification, all members contained the MADS-domain. After classifying of M-type and MIKC-Type family on PlantTFDB, 36 MIKC-type MADS-box candidate members were obtained.

Subsequently, 71 MADS-box family members were identified using the local blast (ftp://ftp.ncbi. nlm.nih.gov/blast/executables/blast+/LATEST/). It was found that eight members contained the type II specific K-domain, without MADS-domain, so they were discarded. Through classification analysis on PlantTFDB, 36 MIKC-type MADS-box members were obtained.

Based on the identification and classification of above two methods, a total of 36 MIKC-type MADS-box genes were identified in pomegranate, which were renamed as PgMADS01 PgMADS36 according to the gene sequence number [13], for convenience in subsequent analysis (Table 1). 
Table 1. The basic information of the pomegranate MIKC-type MADS-box gene family

\begin{tabular}{|c|c|c|c|c|c|c|c|c|c|}
\hline Gene Name & Gene ID & Location & CDS (bp) & Exon No. & Strand & $\begin{array}{c}\text { Amino Acid } \\
\text { Residues }\end{array}$ & MW(Da) & PI & Subfamily \\
\hline PgMADS01 & Pg000170.1 & scaffold1:4730801:4734403 & 720 & 7 & - & 239 & 27591.1 & 9.76 & $\mathrm{~A}(\mathrm{AP1} 1-\mathrm{FUL})$ \\
\hline PgMADS02 & Pg001270.1 & scaffold10:781136:787463 & 576 & 5 & - & 191 & 22251.1 & 8.76 & SOC1 \\
\hline PgMADS03 & Pg002695.1 & scaffold11:837228:841996 & 846 & 7 & - & 281 & 31958.1 & 8.19 & $\mathrm{E}(\mathrm{SEP})$ \\
\hline PgMADS04 & Pg002696.1 & scaffold11:827349:833260 & 600 & 7 & - & 199 & 22764.8 & 9.58 & FLC \\
\hline PgMADS05 & Pg002697.1 & scaffold11:821950:824737 & 603 & 6 & - & 200 & 22793.1 & 10.17 & FLC \\
\hline PgMADSO6 & Pg003192.1 & scaffold111:252873:258483 & 522 & 6 & - & 173 & 20047.1 & 9.59 & $\mathrm{C} / \mathrm{D}(\mathrm{AG})$ \\
\hline PgMADS07 & Pg003228.1 & scaffold111:423542:426294 & 645 & 7 & + & 214 & 24079.5 & 8.95 & AGL12 \\
\hline PgMADS08 & Pg003757.1 & scaffold119:139771:142418 & 639 & 7 & - & 212 & 24900.2 & 9.28 & $\mathrm{~B}(\mathrm{AP} 3-\mathrm{PI})$ \\
\hline PgMADS09 & Pg005184.1 & scaffold13:3171597:3176055 & 741 & 8 & - & 246 & 28261 & 8.58 & $\mathrm{E}(\mathrm{SEP})$ \\
\hline PgMADS10 & Pg005185.1 & scaffold13:3153310:3158145 & 807 & 8 & - & 268 & 30475.7 & 8.8 & A(AP1-FUL) \\
\hline PgMADS11 & Pg006006.1 & scaffold136:390163:393471 & 906 & 9 & - & 301 & 34973.4 & 9.9 & BS \\
\hline PgMADS12 & Pg008155.1 & scaffold16:570614:573248 & 885 & 7 & - & 294 & 33598.8 & 6.39 & AGL15 \\
\hline PgMADS13 & Pg008465.1 & scaffold16:2554235:2556059 & 642 & 7 & + & 213 & 23721.7 & 8.48 & SVP \\
\hline PgMADS14 & Pg008776.1 & scaffold17:2387895:2392008 & 687 & 8 & - & 228 & 25779.9 & 5.52 & SVP \\
\hline PgMADS15 & Pg009904.1 & scaffold184:267398:273943 & 765 & 5 & - & 254 & 28775.2 & 8.88 & $\mathrm{C} / \mathrm{D}(\mathrm{AG})$ \\
\hline PgMADS16 & Pg014226.1 & scaffold24:1271362:1277266 & 504 & 5 & + & 167 & 19349.0 & 5.97 & MIKC $^{*}$ \\
\hline PgMADS17 & Pg014283.1 & scaffold24:2253081:2257895 & 687 & 8 & + & 228 & 25738.3 & 6.53 & SVP \\
\hline PgMADS18 & Pg014451.1 & scaffold25:814656:818749 & 717 & 8 & - & 238 & 27124.6 & 9.52 & AGL6 \\
\hline PgMADS19 & Pg014630.1 & scaffold25:796521:803849 & 654 & 7 & + & 217 & 24695 & 7.93 & SOC1 \\
\hline PgMADS20 & Pg016044.1 & scaffold3:3612017:3628588 & 612 & 7 & - & 203 & 23056.1 & 4.99 & FLC \\
\hline PgMADS21 & Pg016673.1 & scaffold3:3637896:3641838 & 768 & 8 & - & 255 & 29008.8 & 8.85 & $\mathrm{E}(\mathrm{SEP})$ \\
\hline PgMADS22 & Pg017747.1 & scaffold33:1901905:1904548 & 759 & 8 & + & 252 & 28454 & 7.62 & AGL15 \\
\hline PgMADS23 & Pg018533.1 & scaffold37:1603815:1615806 & 837 & 7 & - & 278 & 31322 & 6.89 & FLC \\
\hline PgMADS24 & Pg020204.1 & scaffold40:966778:969371 & 699 & 7 & + & 232 & 26761 & 4.9 & B(AP3-PI) \\
\hline PgMADS25 & Pg020205.1 & scaffold40:971279:973422 & 708 & 7 & + & 235 & 27089.6 & 6.31 & $\mathrm{~B}(\mathrm{AP} 3-\mathrm{PI})$ \\
\hline PgMADS26 & Pg022433.1 & scaffold5:1599117:1601542 & 675 & 7 & - & 224 & 25754 & 9.07 & B(AP3-PI) \\
\hline PgMADS27 & Pg023007.1 & scaffold50:465601:468168 & 750 & 7 & + & 249 & 28634.4 & 8.57 & $\mathrm{E}(\mathrm{SEP})$ \\
\hline PgMADS28 & Pg023008.1 & scaffold50:480602:487666 & 699 & 7 & + & 232 & 26732.3 & 9.43 & $\mathrm{~A}(\mathrm{AP1} 1-\mathrm{FUL})$ \\
\hline PgMADS29 & Pg024984.1 & scaffold60:1113804:1120065 & 753 & 8 & - & 250 & 28461.2 & 9.5 & $\mathrm{E}(\mathrm{SEP})$ \\
\hline PgMADS30 & Pg026995.1 & scaffold7:90410:99792 & 1974 & 11 & + & 657 & 74414.5 & 9.56 & $\mathrm{C} / \mathrm{D}(\mathrm{AG})$ \\
\hline PgMADS31 & Pg027190.1 & scaffold71:566889:578438 & 654 & 7 & + & 217 & 24935.5 & 9.15 & SOC1 \\
\hline PgMADS32 & Pg027284.1 & scaffold72:255144:257303 & 528 & 6 & - & 175 & 20534.3 & 10.89 & TM8 \\
\hline PgMADS33 & Pg028066.1 & scaffold79:321847:329529 & 672 & 8 & - & 223 & 25020.5 & 10.39 & SVP \\
\hline PgMADS34 & Pg028180.1 & scaffold8:2827697:2833438 & 663 & 7 & - & 220 & 25172.5 & 10.04 & SOC1 \\
\hline PgMADS35 & Pg029246.1 & scaffold86:465224:468460 & 762 & 7 & - & 253 & 28671.7 & 8.89 & AGL17 \\
\hline PgMADS36 & Pg029338.1 & scaffold86:426938:437880 & 1443 & 13 & - & 480 & 55016.3 & 6.61 & AGL17 \\
\hline
\end{tabular}

Note: CDS—coding sequence; MW—-molecular weight. 
The physicochemical properties of 36 MIKC-type MADS-box amino acid sequences were analyzed. The results were shown in Table 1 . The length of the pomegranate MIKC-type genes varied greatly. The shortest length of the encoded protein was $167 \mathrm{aa}$, the longest was $657 \mathrm{aa}$. The corresponding protein molecular mass was between 19,349.0 74,414.5 Da, the average molecular weight was 28,553.23 Da. The isoelectric point (PI) ranged from 4.9 (PgMADS24) to 10.89 (PgMADS32), which contained nine acidic proteins and 27 basic proteins. These results would provide a theoretical basis for PgMADS protein purification and functional research.

\subsection{Phylogenetic Analysis of Pomegranate MIKC-Type MADS-Box Family}

To study the phylogenetic relationships in MIKC-type MADS-box proteins, these protein sequences of pomegranate, Arabidopsis and poplar were used to construct the phylogenetic tree (Figure 1). In this study, the phylogenetic tree was divided into 14 subfamilies, according to Díaz-Riquelme et al. [15] and Leseberg et al. [46]. Among the 36 type II members, only PgMADS16 was classified as MIKC*. The other 35 members were classified as $\mathrm{MIKC}^{\mathrm{C}}$, whcih were divided into 13 subclasses. Among the 13 subfamilies, E (SEP) contained five members; SOC1, B (AP3-PI), and SVP each contained four members; C/D (AG), A (FUL) and FLC contained three member genes; AGL17 had two members. The group of AGL12, AGL6, BS, AGL15, and TM8 subfamilies had only one gene.

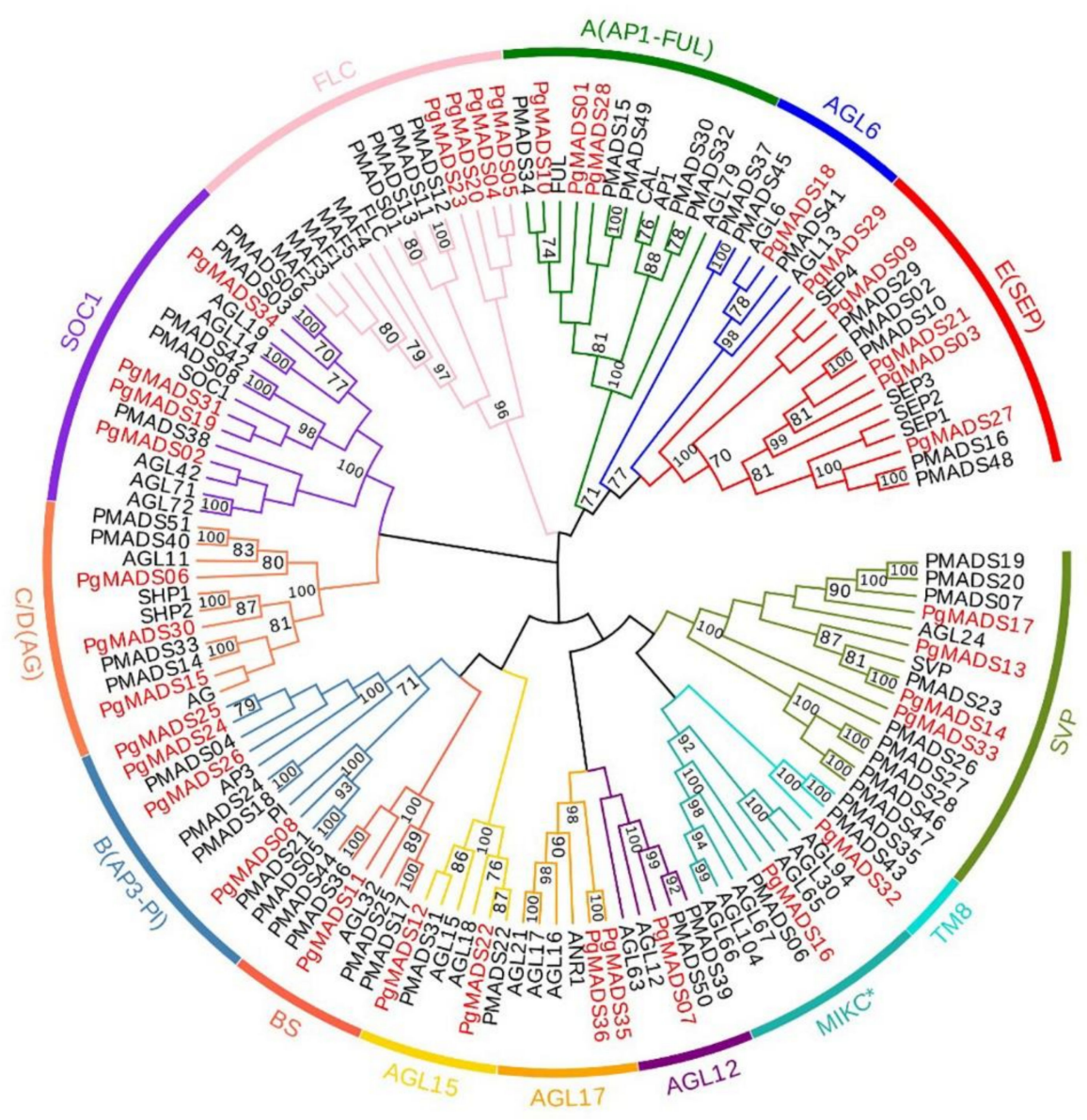

Figure 1. Phylogenetic tree of the MIKC-type MADS-box gene family in pomegranate (PgMADS), poplar (PMADS) and Arabidopsis.

3.3. Gene Structure Analysis and Motif Identification of Pomegranate MIKC-Type MADS-Box Family

In the prediction of conservative motifs of MIKC-type MADS-box members, 10 conservative motifs were identified in pomegranate (Figure 2). According to the distribution and number of motifs, the number of conservative motifs of MIKC-type MADS-box protein varied greatly in pomegranate. 
Only PgMADS16 contained two conservative motifs, while PgMADS36 contained 12. The SMART analysis showed that motif 1 was the typical MADS-domain, consisting of about 60 amino acids, and motif 2 was located in the K-box domain. All PgMADS proteins contain motif 1. Except for PgMADS05, PgMADS20, PgMADS16, and PgMADS6, other members contained motifs 3 with unknown functions. Besides PgMADS28, PgMADS01, PgMADS04, PgMADS16, and PgMADS02, other members contained conservative motif 4. Motif 5 only existed in A, E, AGL6 and AGL12 subfamilies. Motif 8 was shared by BS, SOC1, and AGL17. It was worth noting that the K-box domain was not found in PgMADS16, but there was a specific K-box motif 2 .

The gene structures were investigated on the gene structure display server (GSDS). The length of genes ranged from $2 \mathrm{~kb}$ to $17 \mathrm{~kb}$. Among $36 \mathrm{PgMADSs}$, there were 18 genes composed of 6 introns and seven exons, accounting for 50\%. PgMADS36 with 12 introns contains the most exons. Comparative analysis showed that the introns of TM8, BS, AGL15, and B subgroup genes were shorter, resulting in the shorter length of their genes than other subfamilies. Most FLC members had longer introns than other subfamily genes. The number of exons was seven in the B subfamily. The number of introns of the C/D class ranged from four (PgMADS15) to 10 (PgMADS30).

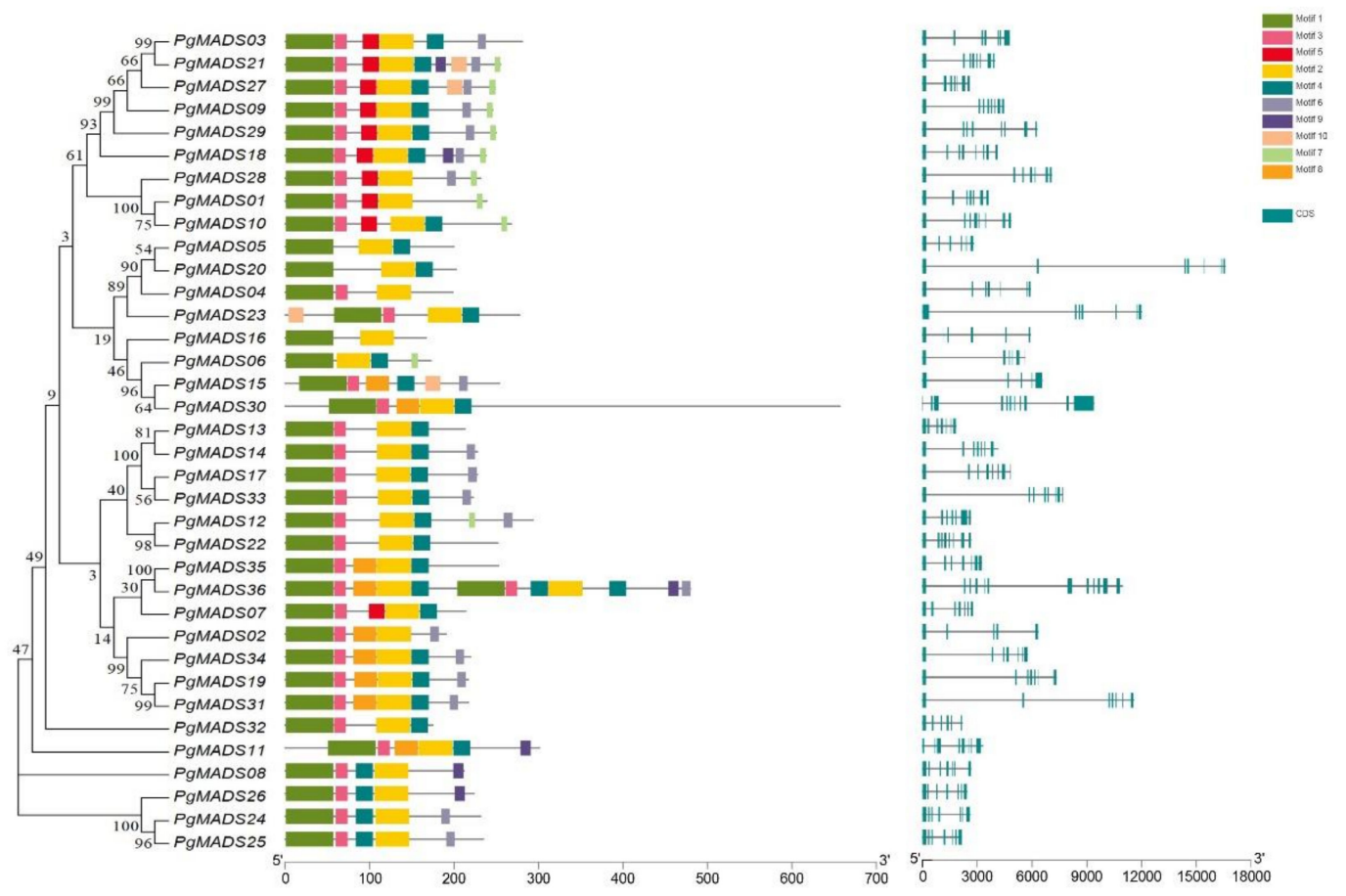

Figure 2. Phylogenetic tree, gene structure and conservative protein motifs of the MIKC-type MADS-box family in pomegranate.

\subsection{Prediction Promoter Elements of the Pomegranate MIKC-Type MADS-Box Family}

In this study, the cis-element analysis showed that promoters of PgMADSs contained a wide variety of cis-acting elements, ranging from 18 cis-acting elements in PgMADS29 to 30 in PgMADS30 (Figure 3). PgMADSs responded to different plant hormones and abiotic stress signals, including abscisic acid response elements (ABRE) [47], gibberellin response elements (GARE-motif, TATC-box and P-box) [48], auxin response elements (TGA-element, AuxRR-core, TGA-box and AuXRE) [49], methyl jasmonate response elements (TGACG-motif and CGTCA-motif) [50], salicylic acid response elements (TCA-element) [51], and stress-related response elements (ARE, TC-rich repeats, WUN-motif, LTR and MBS) [52]. The ABRE element was abundant in pomegranate, with 19 genes containing two or more ABRE. PgMADS13 promoter sequence contained up to $10 \mathrm{ABRE}$, indicating a strong response to the abscisic acid signal. Many members contained gibberellin response elements, such as the 
GARE-motif of $P g M A D S 01$ in subfamily A, the TATC-box of $P g M A D S 09$ in subfamily E, and the P-box of PgMADS07 in subfamily AGL12. Except for AGL12 and TM8 subfamilies without LTR, other genes contained LTR elements. PgMADS21 and PgMADS35 contained two drought-induced MYB binding sites MBS. There were 15 genes containing auxin response elements, among which PgMADS28 and PgMADS12 contained two TGA-elements, while PgMADS05 contained both TGA-element and AuxRE. $P g M A D S s$ were rich in methyl jasmonate and salicylic acid response elements. In addition to the AGL12 subfamily, the remaining genes of the AGL12 family contained one or more methyl jasmonate and salicylic acid response elements.

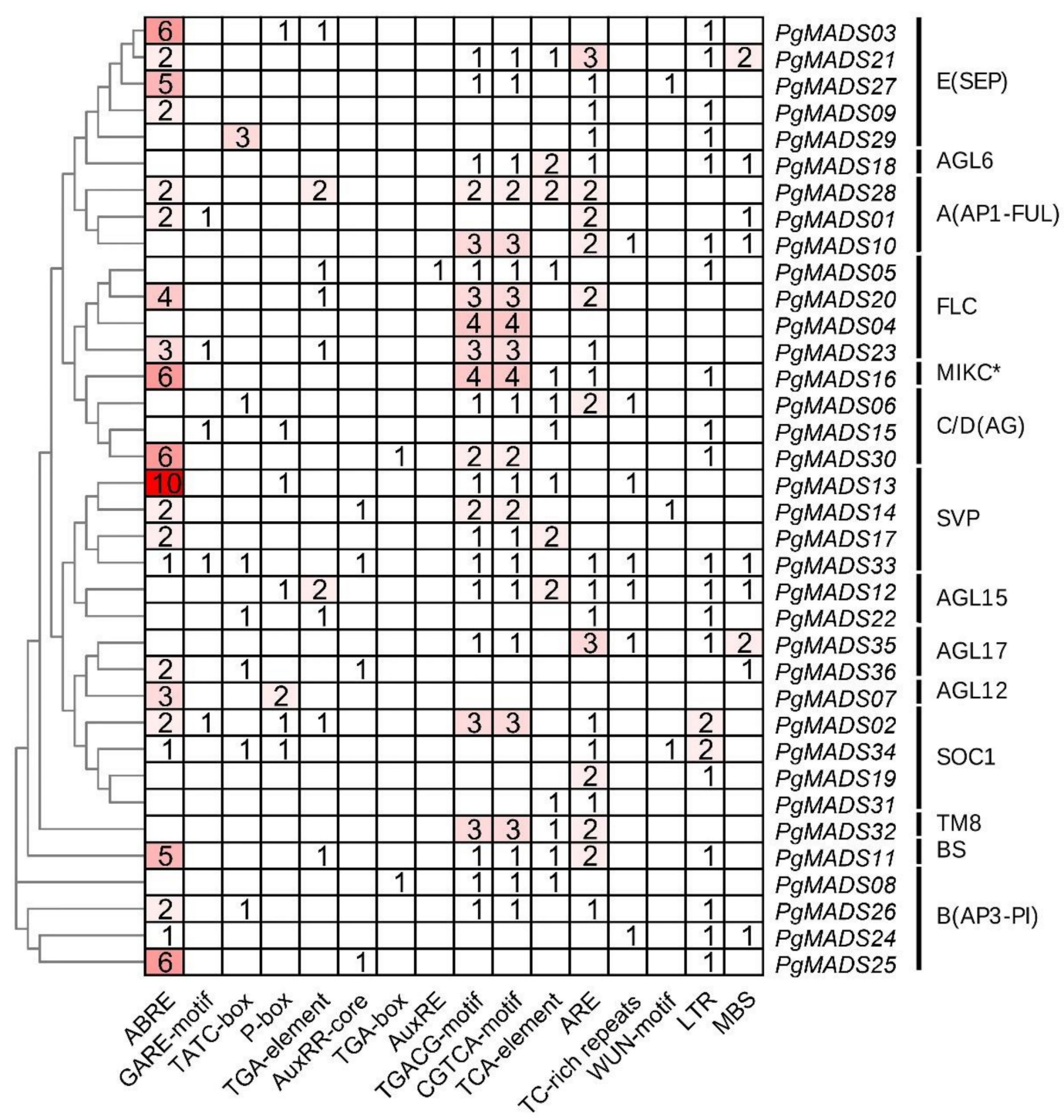

Figure 3. Analysis of Cis-acting elements of MIKC-type MADS-box gene family in pomegranate. ABRE is abscisic acid response element; P-box, TATC-box and GARE-motif are gibberellin response element; AuxRE and AuxRR are regulatory auxin responsiveness element; TGA-element and TGA-box are auxin response element; ARE is antioxidant response element; CGTCA-motif methyl jasmonate response element; LTR is cold stress response element; TCA-motif is salicylic acid response element; TGACG-motif is jasmonate response element. TC-rich repeats are cis-acting elements that respond to defense and stress responses; WUN-motif wound response elements; MBS is the drought resistance-induced MYB binding site. 


\subsection{Protein Interaction Networks of the Pomegranate MIKC-Type MADS-Box Family}

The protein interaction between MIKC-type PgMADSs was analyzed to know potential functions and signal transduction or metabolic pathways. The result showed a close interaction among $\mathrm{A}, \mathrm{B}$, $\mathrm{C} / \mathrm{D}$, and E types, among which the C/D genes (PgMADS30, PgMADS15 and PgMADS06) also had an interaction relationship (Figure 4). PgMADS15 was located at the core of the interaction network and interacted with A, B, and E types genes. PgMADS15 had stronger interaction with PgMADS06, PgMADS09, PgMADS27, and PgMADS29.

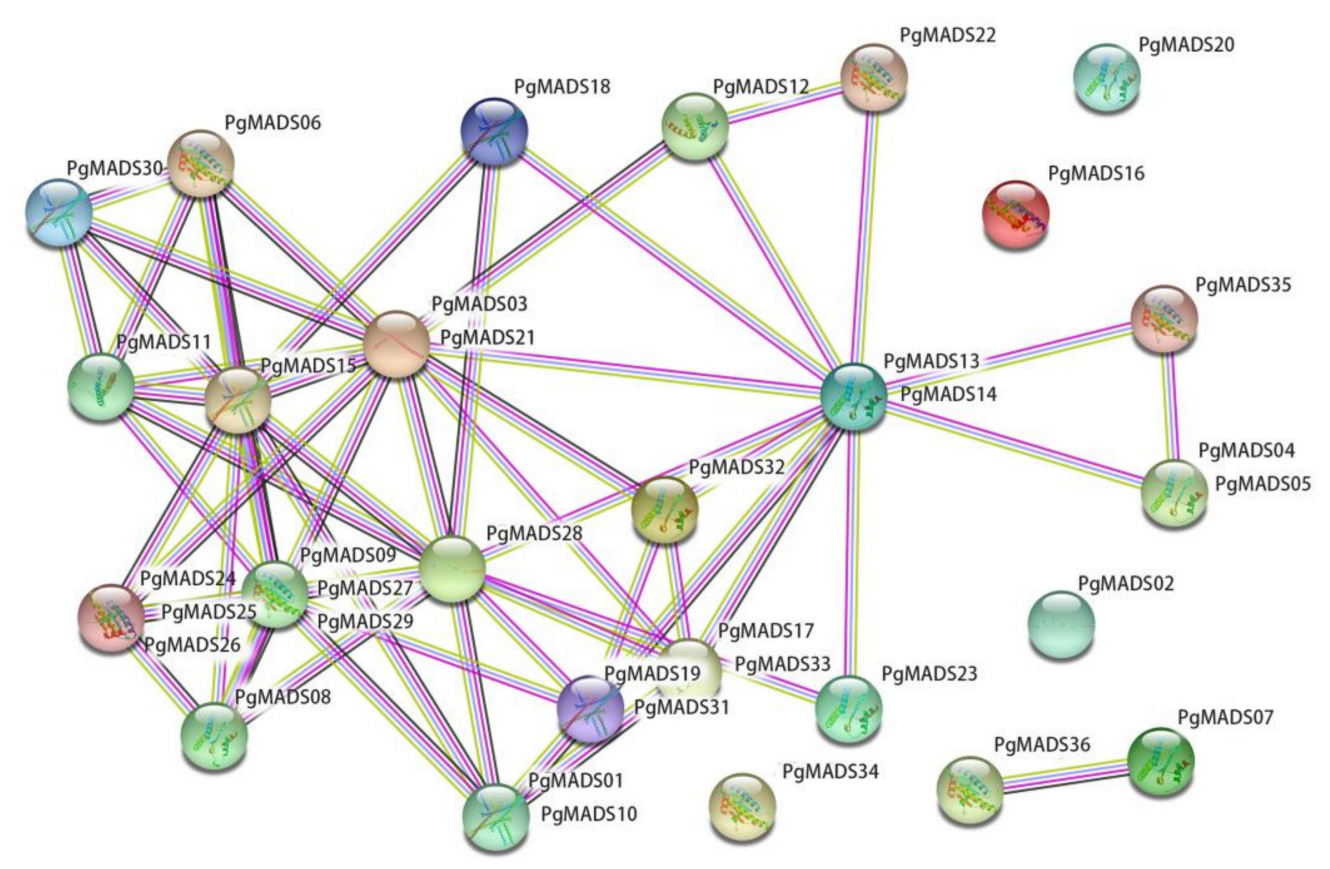

Figure 4. Protein-protein interaction network of MIKC-type MADS-box family in pomegranate.

Class B genes can form homologous dimers, but they steadily play function when they have formed heterodimers with AP3 and PI [53]. There was an interaction between AP3 (PgMADS24, PgMADS25, PgMADS26) and PI (PgMADS08) in pomegranate. E class genes could interact with multiple genes. When MIKC-type MADS-box protein formed a polymer, E genes acted as a 'binder' binds the dimer complex formed to form a polymer [25,26]. PgMADS03 and PgMADS21 belonging to $\mathrm{E}$ interacted with $\mathrm{A}, \mathrm{B}$ and $\mathrm{C} / \mathrm{D}$ classes genes, indicating that $\mathrm{E}$ genes might play an essential role in the formation of MIKC complexes related to the organ development of pomegranate flower.

According to the PgMADSs family protein interaction network, PgMADS15 was at the core of the interaction network. The study further analyzed the protein network of PgMADS15 in flower development, with the results shown in Figure 5. PgMADS15 had high similarity with Arabidopsis AtAG (bit score 247.7, e-value 7.9 $\mathrm{E}^{-66}$ ). AG interacted with LFY (LEAFY) and AP2 proteins to regulate the flowering transition. AG, BEL1 and SUP coordinated to regulate ovule development. AG interacted with uncertain function proteins such as HUA1, ICU2, and LUG. It is predicted that PgMADS15 had the function of regulating flowering, ovule, and other flower organ development. 


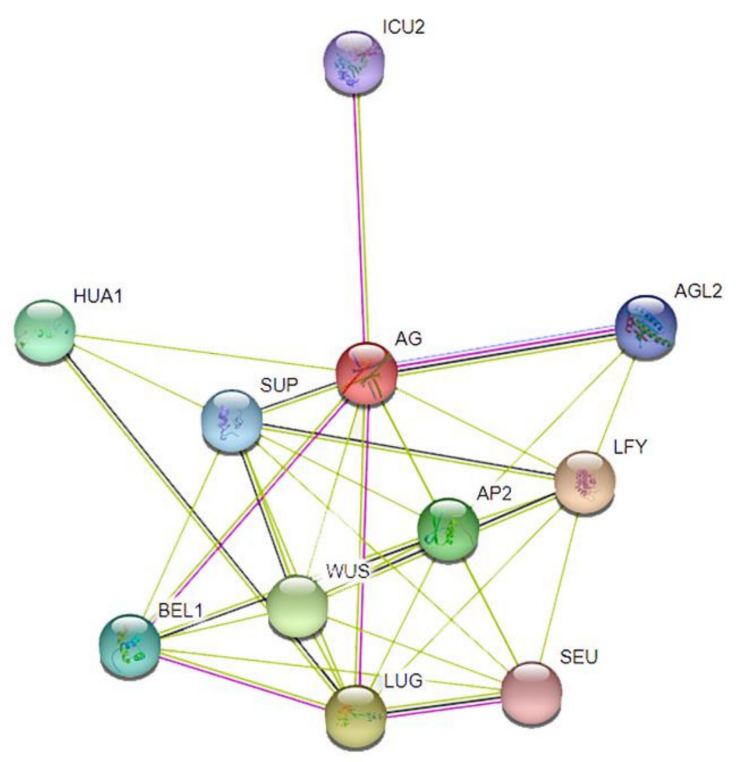

Figure 5. Protein interaction network of PgMADS15 in pomegranate.

\subsection{Expression Analysis for Pomegranate MIKC-Type MADS-Box Family}

According to the published transcriptome data, MIKC-type MADS-box genes are expressed in leaf, root, flower, fruit, endocarp, and pericarp (Figure 6). There were remarkable differences in tissue-specific expression and expression quantity. Significant differences were also found in the expression quantities of different subfamily genes of MIKC-type MADS-box (Figure 6a). The expression levels of $\mathrm{E}$ genes were the highest in flower organs, followed by $\mathrm{C} / \mathrm{D}$ subfamily genes. Most genes of other subfamilies were low or not expressed in leaves and roots. The analysis found that the expression levels of the same subfamily genes in different tissues exhibited obvious differences, such as E-type genes. PgMADS03 and PgMADS21 were not expressed in root and leaf, while they were highly expressed in all tissues of pomegranate flower organs. PgMADS09 was not expressed in leaves, roots, and inner/outer seed skins, while PgMADS29 was almost not expressed in all tissues. These results indicated that the function of E genes might occur differentiation. PgMADS06 and PgMADS30 of C/D subfamily genes showed similar tissue-specific expression patterns, but PgMADS15 was not expressed in functional male flowers and bisexual flowers. PgMADS17, PgMADS19, PgMADS31, and $P g M A D S 34$ were only expressed in leaves and roots, indicating that the C/D subfamily genes of MADS-box expression were highly specific.

According to the differences in expression patterns, cluster analysis was carried out in the MIKC-type MADS-box family, with the results shown in Figure 6b. The obtained 36 genes can be divided into three groups. The genes in group I was highly expressed in flowers, mixtures, seed coats and peels, indicating that these genes play essential roles in the development of flowers and fruits. The expression levels of group II genes were lower than that in group I and III genes, and the genes of the second subgroup in group II were highly expressed in roots and leaves. The expression levels of group III genes were higher than in other groups in floral organ development. Cluster expression analysis showed that different subfamilies genes might have similar expression patterns, such as the E gene (PgMADS03, PgMADS21, and PgMADS27) and C/D gene (PgMADS06 and PgMADS30). They were not expressed or behaved at a low expression level in roots and leaves, but were highly expressed in other tissues. 

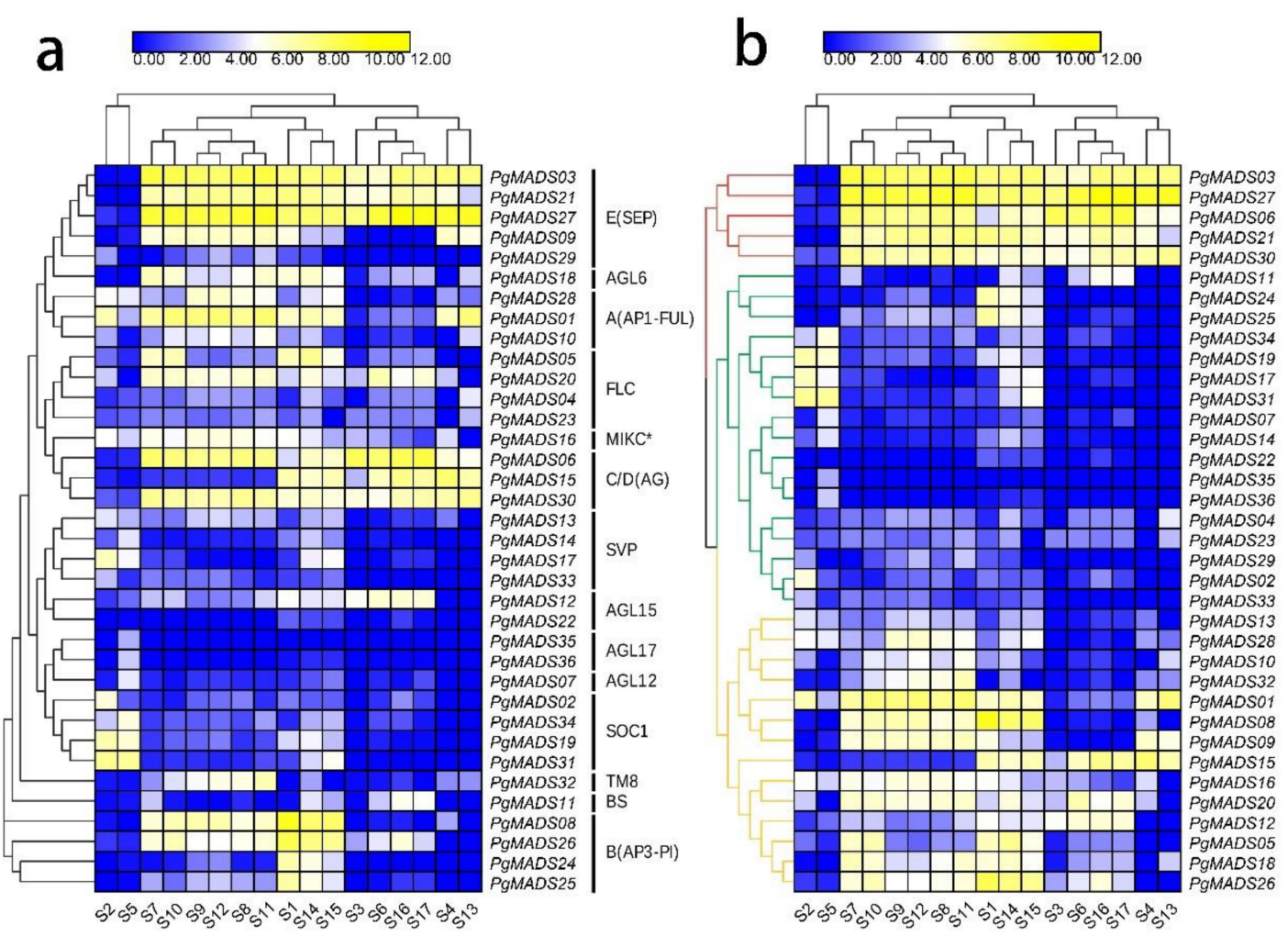

Figure 6. The heatmap of MIKC-type MADS-box family gene expression in different organs of pomegranate. Note: (a). Gene expression patterns of different subfamilies genes; (b). Hierarchical clustering of gene expression patterns. S1: flower; S2: leaf; S3: outer seed coat; S4: peel; S5: root; S6: inner seed coat; S7: functional male flower I; S8: functional male flower II; S9: functional male flower III; S10: bisexual Flower I; S11: bisexual Flower II; S12: bisexual Flower III; S13: 'Wonderful' peel; S14: a mixture of 'nana' flowers, leaves, fruits and roots; S15: a mixture of 'Black127' flowers, leaves, fruits and roots; S16: 'Baiyushizi' inner seed coat; S17: 'Tunisia' inner seed coat.

\section{Discussion}

In the plants, MIKC-type MADS-box transcription factors contain MADS-domain and K-box domain, and play important roles in flowering and floral organ development [54,55]. In recent years, the identification and evolutionary analysis of the MIKC-type MADS-box family have been reported in many species, such as 32 members in Prunus mume [13], 33 members in Fragaria vesca [56], 38 members in Vitis vinifera [15], 39 members in Prunus persica [57], 72 members in Glycine max [58], and 82 genes in Malus domestica [59]. Genomic data of three pomegranate varieties have been published on the NCBI database, but the identification and analysis of the MIKC-type MADS-box family have not been reported. In this study, a total of 36 candidate MIKC-type MADS-box genes were identified in pomegranate. Members were encoded with 167-657 amino acids. The 36 MIKC-type MADS-box members in pomegranate were far fewer than 201 in Triticum aestivum and 94 in Nicotiana tabacum $[60,61]$. The differences in the number of members may be due to the fact that tobacco and wheat are polyploid, while pomegranate being polyploid [29,62]. According to the phylogenetic relationships of MIKC-type MADS-box genes between Arabidopsis and poplar, PgMADS genes were divided into 13 distinct clades, including TM8 subfamily which was not found in Arabidopsis.

According to the analysis of gene structure, PgMADS genes contained 5-12 introns, and seven exons were the main structure of PgMADSs. The genetic structure of PgMADSs was consistent with that of Arabidopsis, apples, and soybeans $[11,58,59]$, indicating that MIKC-type MADS-box gene structure is relatively conserved. Conservative sequence analysis of 36 MIKC-type MADS-box genes showed that members of the same subfamily had the same number of motifs and similar sequences, while there were some differences in the number of motifs between subfamilies. Also, members of the 
same subfamily have certain similarities in gene structure, and these results support the findings of the subfamily classification of pomegranate MIKC-type MADS-box family. The conservative motif 1 encodes the MEF2-type MADS-domain, which is the most conserved domain. Motif 2 encodes the $\mathrm{K}$-box domain, which is the second most conservative in PgMADS family. In general, the K-box motif exists only in the MIKC ${ }^{C}$ subfamily [10], but there is motif 2 in MIKC* type PgMADS16. The gene structure of MIKC ${ }^{*}$ and MIKC ${ }^{C}$ family is similar. M $\delta$ of type I genes is also treated as a type II gene in Arabidopsis and rice, so it is called the MIKC* type gene [12,63]. MIKC*-type genes share the characteristics of both M-type and MIKC ${ }^{C}$ family. Furthermore, the evolutionary tree of M $\delta$ is different from $\mathrm{M} \alpha, \mathrm{M} \beta$, and $\mathrm{M} \gamma$, but it is similar to that of MIKC-type [13,64]. It was speculated that the MIKC* subfamily might be the transitional form in the evolution of MADS-box genes. Xu et al. put forward a similar view that $\mathrm{MIKC}^{\mathrm{C}}$ subfamily lost $\mathrm{K}$-domain, while retained more introns, making it became MIKC* subfamily [13]. With the further loss of introns, MIKC* subfamily became an M-type subfamily with shorter sequences and fewer introns [13].

Cis-acting elements exist in the gene promoters and form specific binding with transcription factors and play important roles in regulating the expression of target genes [65]. The promoter sequence of the MIKC-type MADS-box gene contains multiple cis-acting elements related to hormone response and abiotic stress, which are rich in methyl jasmonate response elements and abscisic acid response elements. This result is consistent with that by research reports on grape and Phyllostachys edulis $[66,67]$, indicating that the promoter regulatory element of the MADS-box gene has a certain conservatism among different species. Previous studies have found that ABRE is associated with drought, ABA induction, and high salt stress in plants [68,69]. There were many ABRE elements in PgMADS13, PgMADS03, PgMADS16, PgMADS30, and PgMADS25, which were speculated to be related to pomegranate response to drought, $\mathrm{ABA}$ induction or high salt stress. MIKC-type MADS-box gene also contains other elements such as TGA-element, TATC-box, TGACC-motif, and TCA-element, indicating that the MIKC-type MADS-box gene can respond to the regulation of hormones such as auxin, gibberellin, jasmonic acid, and salicylic acid, which are involved in plant growth and development and plant stress response. These results suggest that MIKC-type MADS-box family genes may play essential roles in pomegranate's growth and development of pomegranate and in response to abiotic stress.

Studies have shown that the MADS-box gene play roles in the development of floral organs by forming homologous or heterologous complexes [70]. An analysis of the protein network of MIKC-type MADS-box family showed that there was the interaction among the MIKC-type MADS-box members, indicating that they might jointly regulate flower development by forming heterologous complexes. We also found that PgMADS15 occupied a vital position in the protein interaction network, indicating $P g M A D S 15$ played a crucial role in the regulation network of flower development.

Analysis of the expression pattern of MIKC-type MADS-Box gene found that PgMADS17, PgMADS19, PgMADS31, and PgMADS34 were only expressed in leaves and roots, while other members were expressed in flower tissues. The results indicated that the MIKC-type MADS-box gene might be participated in pomegranate development regulation of different tissues. E subfamily genes (PgMADS03, PgMADS21, PgMADS27) and C/D subfamily genes (PgMADS06 and PgMADS30) were highly expressed in various tissues of pomegranate flower organs, but not in leaves and roots, indicating that $\mathrm{C} / \mathrm{D}$ and $\mathrm{E}$ subfamily genes were highly expressed specifically in pomegranate. Studies have shown that AP1-FUL, AP3-PI, AG, and AGL6 subfamilies genes regulate floral organ development in Arabidopsis, and the different subfamilies genes of MIKC-type MADS-box present similar expression patterns in different species [14,71,72]. AP1-FUL, AP3-PI, AG and AGL6 subfamilies genes have high expression levels in the pomegranate bisexual flowers, proving that these genes might be involved in the regulation of floral organ development in pomegranate. In Arabidopsis thaliana, the fruit differentiation and development are regulated by the C/D (AGL11, SHP1/SHP2) and A(AP1-ful) class genes [73,74]. Reports found that FaMADS9, a member of the strawberry E(SEP) class, was also involved in fruit development and maturation [75]. E class genes (PgMADS03, PgMADS21, PgMADS27, PgMADS09), 
C/D class (PgMADS06, PgMADS15, PgMADS30), and A class (PgMADS01) were highly expressed in pomegranate peel, indicating that these genes might play important roles in pomegranate fruit development. The study showed that the same subfamily genes had different expression patterns, and the $C / D$ genes regulated the development of carpel and ovule [21,76]. In pomegranate, the $C$ gene $P g M A D S 06$ and D gene PgMADS30 were highly expressed at three development stages of functional male and bisexual flower, while the D gene PgMADS15 was not expressed, suggesting that PgMADS15 may lose some functions in the evolution and development of species.

\section{Conclusions}

Herein, 36 MIKC-type MADS-box genes were identified in pomegranate, and the necessary information concerning these genes was analyzed by bioinformatics to explore their phylogenetic relationship and their functions in the development of flower organs. The gene structure and conserved domain of $36 P g M A D S s$ were analyzed, showing that the same subfamilies' gene structures were relatively similar. Cis-acting element analysis showed that promoter sequences of PgMADS genes contained multiple hormone response and abiotic stress related elements, suggesting that PgMADSs might be closely related to plant hormone signal transduction and adverse situations. It was speculated that $P g M A D S s$ might be related to the growth and development of pomegranate. Protein interaction network analysis found that PgMADS15 was located at the core of the interaction network. Combining the analysis of tissue specific expressions, PgMADS15 was highly expressed in the peel and inner seed coat. It was concluded that $P g M A D S 15$ might play an essential role in the peel and inner seed coat development of pomegranate. Our conclusions will lay the foundation for further research on the function of the MIKC-type MADS-box gene in pomegranate, primarily providing a reference for the analysis of the gene function regulating the development of flower organs.

Supplementary Materials: The following are available online at http:/www.mdpi.com/2073-4395/10/8/1197/s1, Table S1: RNA-Seq data of pomegranate.

Author Contributions: Conceptualization, Y.Z. and H.Z.; methodology, Y.Z. and H.Z.; investigation, Y.Z. and H.Z.; writing-original draft preparation, Y.Z. and H.Z.; writing-review and editing, Y.Z., Y.W., X.Z. (Xinhui Zhang), X.Z. (Xueqing Zhao), and Z.Y.; supervision, Z.Y.; funding acquisition, Z.Y. All authors have read and agreed to the published version of the manuscript.

Funding: This research was funded by the Initiative Project for Talents of Nanjing Forestry University [GXL2014070, GXL2018032], the Priority Academic Program Development of Jiangsu High Education Institutions [PAPD], the National Natural Science Foundation of China (31901341), and the Natural Science Foundation of Jiangsu Province [BK20180768].

Acknowledgments: Y.Z. and H.Z. are co-first authors.

Conflicts of Interest: The authors declare no conflict of interest.

\section{References}

1. Becker, A.; Theissen, G. The major clades of MADS-box genes and their role in the development and evolution of flowering plants. Mol. Phylogenet. Evol. 2003, 29, 464-489. [CrossRef]

2. Messenguy, F.; Dubois, E. Role of MADS-box proteins and their cofactors in combinatorial control of gene expression and cell development. Gene 2003, 316, 1-21. [CrossRef]

3. Alvarezbuylla, E.R.; Pelaz, S.; Liljegren, S.J.; Gold, S.E.; Burgeff, C.; Ditta, G.S.; De Pouplana, L.R.; Martinezcastilla, L.P.; Yanofsky, M.F. An ancestral MADS-box gene duplication occurred before the divergence of plants and animals. Proc. Natl. Acad. Sci. USA 2000, 97, 5328-5333. [CrossRef]

4. Smaczniak, C.; Immink, R.G.H.; Angenent, G.C.; Kaufmann, K. Developmental and evolutionary diversity of plant MADS-domain factors: insights from recent studies. Development 2012, 139, 3081-3098. [CrossRef] [PubMed]

5. Sommer, H.; Beltran, J.P.; Huijser, P.; Pape, H.; Lonnig, W.; Saedler, H.; Schwarzsommer, Z.D. A homeotic gene involved in the control of flower morphogenesis in Antirrhinum majus: the protein shows homology to transcription factors. EMBO J. 1990, 9, 605-613. [CrossRef] [PubMed] 
6. Yanofsky, M.F.; Ma, H.; Bowman, J.L.; Drews, G.N.; Feldmann, K.A.; Meyerowitz, E.M. The protein encoded by the Arabidopsis homeotic gene agamous resembles transcription factors. Nature 1990, 346, 35-39. [CrossRef] [PubMed]

7. Ma, H. Molecular genetic analyses of microsporogenesis and microgametogenesis in flowering plants. Annu. Rev. Plant. Biol. 2005, 56, 393-434. [CrossRef]

8. Chi, Y.; Huang, F.; Liu, H.; Yang, S.; Yu, D. An APETALA1-like gene of soybean regulates flowering time and specifies floral organs. J. Plant. Physiol. 2011, 168, 2251-2259. [CrossRef]

9. Galimba, K.D.; Stilio, V.S.D. Sub-functionalization to ovule development following duplication of a floral organ identity gene. Dev. Biol. 2015, 405, 158-172. [CrossRef]

10. Gao, Y.; Sun, J.; Sun, Z.; Xing, Y.; Zhang, Q.; Fang, K.; Cao, Q.; Qin, L. The MADS-box transcription factor CmAGL11 modulates somatic embryogenesis in Chinese chestnut (Castanea mollissima Blume). J. Integr. Agric. 2020, 19, 1033-1043. [CrossRef]

11. Parenicova, L.; De Folter, S.; Kieffer, M.; Horner, D.S.; Favalli, C.; Busscher, J.; Cook, H.; Ingram, R.; Kater, M.M.; Davies, B. Molecular and phylogenetic analyses of the complete MADS-box transcription factor family in Arabidopsis: New Openings to the MADS World. Plant Cell 2003, 15, 1538-1551. [CrossRef] [PubMed]

12. Arora, R.; Agarwal, P.; Ray, S.; Singh, A.K.; Singh, V.P.; Tyagi, A.K.; Kapoor, S. MADS-box gene family in rice: genome-wide identification, organization and expression profiling during reproductive development and stress. BMC Genom. 2007, 8, 242. [CrossRef]

13. Xu, Z.; Zhang, Q.; Sun, L.; Du, D.; Cheng, T.; Pan, H.; Yang, W.; Wang, J. Genome-wide identification, characterisation and expression analysis of the MADS-box gene family in Prunus mume. Mol. Genet. Genom. 2014, 289, 903-920. [CrossRef] [PubMed]

14. Henschel, K.; Kofuji, R.; Hasebe, M.; Saedler, H.; Munster, T.; Theissen, G. Two ancient classes of MIKC-type MADS-box genes are present in the Moss Physcomitrella Patens. Mol. Biol. Evol. 2002, 19, 801-814. [CrossRef] [PubMed]

15. Díaz-Riquelme, J.; Lijavetzky, D.; Martinezzapater, J.M.; Carmona, M.J. Genome-wide analysis of MIKC ${ }^{\mathrm{C}}$-Type MADS-box genes in grapevine. Plant Physiol. 2009, 149, 354-369. [CrossRef]

16. Heijmans, K.; Morel, P.; Vandenbussche, M. MADS-box genes and floral development: the Dark Side. J. Exp. Bot. 2012, 63, 5397-5404. [CrossRef]

17. Theisen, G.; Melzer, R.; Rumpler, F. MADS-domain transcription factors and the floral quartet model of flower development: linking plant development and evolution. Development 2016, 143, 3259-3271. [CrossRef]

18. Martín-Pizarro, C.; Triviño, J.C.; Posé, D. Functional analysis of TM6 MADS-box gene in the octoploid strawberry by CRISPR/Cas9 directed mutagenesis. J. Exp. Bot. 2019, 70, 885-895. [CrossRef]

19. Winter, K.; Becker, A.; Munster, T.; Kim, J.T.; Saedler, H.; Theissen, G. MADS-box genes reveal that gnetophytes are more closely related to conifers than to flowering plants. Proc. Natl. Acad. Sci. USA 1999, 96, 7342-7347. [CrossRef]

20. Chen, X. A MicroRNA as a Translational Repressor of APETALA2 in Arabidopsis Flower Development. Science 2004, 303, 2022-2025. [CrossRef]

21. Xu, Z.; Zhong, K. Plant Cell Differentiation and Organogenesis; Science Press: Biejing, China, 2015.

22. Ehlers, K.; Bhide, A.S.; Tekleyohans, D.G.; Wittkop, B.; Snowdon, R.J.; Becker, A. The MADS-box genes ABS, $S H P 1$, and SHP2 are essential for the coordination of cell divisions in ovule and seed coat development and for endosperm formation in Arabidopsis thaliana. PLoS ONE 2016, 11, e0165075. [CrossRef] [PubMed]

23. Pan, I.L.; McQuinn, R.; Giovannoni, J.J.; Irish, V.F. Functional diversification of AGAMOUS lineage genes in regulating tomato flower and fruit development. J. Exp. Bot. 2010, 61, 1795-1806. [CrossRef] [PubMed]

24. Xu, Y.; Zhang, L.; Xie, H.; Zhang, Y.; Oliveira, M.M.; Ma, R. Expression analysis and genetic mapping of three SEPALLATA-like genes from peach (Prunus persica (L.) Batsch). Tree Genet. Genomes 2008, 4, 693-703. [CrossRef]

25. Melzer, R.; Theissen, G. Reconstitution of 'floral quartets' in vitro involving class B and class E floral homeotic proteins. Nucleic Acids Res. 2009, 37, 2723-2736. [CrossRef] [PubMed]

26. Pan, Z.J.; Chen, Y.Y.; Du, J.S.; Chen, Y.Y.; Chung, M.C.; Tsai, W.C.; Wang, C.; Chen, H. Flower development of phalaenopsis orchid involves functionally divergent SEPALLATA-like genes. New Phytol. 2014, 202, 1024-1042. [CrossRef] [PubMed] 
27. Honma, T.; Goto, K. Complexes of MADS-box proteins are sufficient to convert leaves into floral organs. Nature 2001, 409, 525-529. [CrossRef]

28. Yuan, Z.H. Chinese Fruit Tree Science and Practice-Pomegranate; Shaanxi Science and Technology Press: Xi'an, China, 2015; pp. 1-10.

29. Holland, D.; Hatib, K.; Bar-Yaakov, I. Pomegranate: botany, horticulture, breeding. In Horticultural Review; John Wiley \& Sons Inc.: Hoboken, NJ, USA, 2009; Volume 35, pp. 127-191.

30. Huang, T.H.; Peng, G.; Kota, B.P.; Li, G.Q.; Yamahara, J.; Roufogalis, B.D.; Li, Y. Anti-diabetic action of Punica granatum flower extract: activation of PPAR-gamma and identification of an active component. Toxicol. Appl. Pharm. 2005, 207, 160-169. [CrossRef]

31. Lansky, E.P.; Newman, R.A. Punica granatum (pomegranate) and its potential for prevention and treatment of inflammation and cancer. J. Ethnopharmacol. 2007, 109, 177-206. [CrossRef]

32. Basu, A.; Penugonda, K. Pomegranate juice: A heart healthy fruit juice. Nutr. Rev. 2009, 67, 49-56. [CrossRef]

33. Qin, G.; Xu, C.; Ming, R.; Tang, H.; Guyot, R.; Kramer, E.M.; Hu, Y.; Yi, X.; Qi, Y.; Xu, X. The pomegranate (Punica granatum L.) genome and the genomics of punicalagin biosynthesis. Plant J. 2017, 91, 1108-1128. [CrossRef]

34. Yuan, Z.; Fang, Y.; Zhang, T.; Fei, Z.; Han, F.; Liu, C.; Liu, M.; Xiao, W.; Zhang, W.; Wu, S. The pomegranate (Punica granatum L.) genome provides insights into fruit quality and ovule developmental biology. Plant Biotechnol. J. 2018, 16, 1363-1374. [CrossRef] [PubMed]

35. Luo, X.; Li, H.; Wu, Z.; Yao, W.; Zhao, P.; Cao, D.; Yu, H.; Li, K.; Poudel, K.L.; Zhao, D. The pomegranate (Punica granatum L.) draft genome dissects genetic divergence between soft- and hard-seeded cultivars. Plant Biotechnol. J. 2020, 18, 955-968. [CrossRef] [PubMed]

36. Chen, L.N.; Zhang, J.; Li, H.X.; Niu, J.; Xue, H.; Liu, B.B.; Wang, Q.; Luo, X.; Zhang, F.H.; Zhao, D.G.; et al. Transcriptomic analysis reveals candidate genes for female sterility in pomegranate flowers. Front Plant Sci. 2017, 8, 1430. [CrossRef] [PubMed]

37. Ono, N.N.; Britton, M.T.; Fass, J.N.; Nicolet, C.M.; Lin, D.; Tian, L. Exploring the transcriptome landscape of pomegranate fruit peel for natural product biosynthetic gene and SSR marker discovery. J. Integr. Plant Biol. 2011, 53, 800-813. [CrossRef] [PubMed]

38. Ophir, R.; Sherman, A.; Rubinstein, M.; Eshed, R.; Schwager, M.S.; Harel-Beja, R.; Bar-Ya'akov, I.; Holland, D. Single-nucleotide polymorphism markers from de-novo assembly of the pomegranate transcriptome reveal germplasm genetic diversity. PLoS ONE 2014, 9, e88998. [CrossRef]

39. Marchler-Bauer, A.; Bo, Y.; Han, L.; He, J.; Lanczycki, C.J.; Lu, S.; Chitsaz, F.; Derbyshire, M.K.; Geer, R.C.; Gonzales, N.R.; et al. CDD/SPARCLE: functional classification of proteins via subfamily domain architectures. Nucleic Acids Res. 2017, 45, D200-D203. [CrossRef]

40. Jin, J.P.; Zhang, H.; Kong, L.; Gao, G.; Luo, J.C. PlantTFDB 3.0: a portal for the functional and evolutionary study of plant transcription factors. Nucleic Acids Res. 2014, 42, D1182-7. [CrossRef]

41. Gao, H.H.; Zhang, Y.X.; Hu, S.W.; Guo, Y. Genome-wide survey and phylogenetic analysis of MADS-box gene family in Brassica napus. Chin. Bull. Botany 2017, 52, 699-712.

42. Kumar, S.; Stecher, G.; Tamura, K. MEGA7: Molecular evolutionary genetics analysis version 7.0 for bigger datasets. Mol. Biol. Evol. 2016, 33, 1870-1874. [CrossRef]

43. Chen, C.J.; Xia, R.; Chen, H.; He, Y.H. TBtools, a Toolkit for biologists integrating various HTS-data handling tools with a user-friendly interface. BioRxiv 2018. [CrossRef]

44. Chen, S.; Zhou, Y.; Chen, Y.; Gu, J. fastp: an ultra-fast all-in-one FASTQ preprocessor. Bioinformatics 2018, 34, i884-i890. [CrossRef]

45. Nicolas, L.B.; Harold, P.; Páll, M.; Lior, P. Near-optimal probabilistic RNA-seq quantification. Nat. Biotechnol. 2016, 34, 525-527.

46. Leseberg, C.H.; Li, A.L.; Kang, H.; Duvall, M.; Mao, L. Genome-wide analysis of the MADS-box gene family in Populus trichocarpa. Gene 2006, 378, 84-94. [CrossRef] [PubMed]

47. Hobo, T.; Asada, M.; Kowyama, Y.; Hattori, T. ACGT-containing abscisic acid response element (ABRE) and coupling element 3 (CE3) are functionally equivalent. Plant J. 1999, 19, 679-689. [CrossRef] [PubMed]

48. Gubler, F.; Jacobsen, J.V. Gibberellin-responsive elements in the promoter of a barley high-pI alpha-amylase gene. Plant Cell 1992, 4, 1435-1441. [CrossRef] [PubMed]

49. Khan, M.R.; Hu, J.Y.; Ali, G.M. Reciprocal loss of CArG-boxes and auxin response elements drives expression divergence of MPF2-Like MADS-box genes controlling calyx inflation. PloS ONE 2012, 7, e42781. [CrossRef] 
50. Rouster, J.; Leah, R.; Mundy, J.; Cameron-Mills, V. Identification of a methyl jasmonate-responsive region in the promoter of a lipoxygenase 1 gene expressed in barley grain. Plant J. 1997, 11, 513-523. [CrossRef]

51. Shah, J.; Klessig, D.F. Identification of a salicylic acid-responsive element in the promoter of the tobacco pathogenesis-related beta-1,3-glucanase gene, PR-2d. Plant J. 1996, 10, 1089-1101. [CrossRef]

52. Yoshida, H.; Haze, K.; Yanagi, H.; Yura, T.; Mori, K. Identification of the cis-acting endoplasmic reticulum stress response element responsible for transcriptional induction of mammalian glucose-regulated proteins. Involvement of basic leucine zipper transcription factors. J. Biol. Chem. 1998, 273, 33741-33749. [CrossRef]

53. Winter, K.; Weiser, C.; Kaufmann, K.; Bohne, A.; Kirchner, C.; Kanno, A.; Saedler, H.; Theissen, G. Evolution of class B floral homeotic proteins: Obligate heterodimerization originated from homodimerization. Mol. Biol. Evol. 2002, 19, 587-596. [CrossRef]

54. Folter, S.D.; Shchennikova, A.V.; Franken, J.; Busscher, M.; Baskar, R.; Grossniklaus, U.; Angenent, G.C.; Immink, R.G.H. A Bsister MADS-box gene involved in ovule and seed development in petunia and Arabidopsis. Plant J. 2006, 47, 934-946. [CrossRef] [PubMed]

55. Mondragonpalomino, M.; Theisen, G. Conserved differential expression of paralogous DEFICIENS- and GLOBOSA-like MADS-box genes in the flowers of Orchidaceae: refining the 'orchid code'. Plant J. 2011, 66, 1008-1019. [CrossRef] [PubMed]

56. Zhou, H.; Li, G.; Zhao, X.; Kang, Z.; Guo, A. Genome-Wide sequence identification of MADS-box transcription factor gene family from Fragaria vesca and cloning of FaMADS1 gene from F. ananassa Fruit. Plant Phys. J. 2014, 50, 1630-1638.

57. Wells, C.E.; Vendramin, E.; Tarodo, S.J.; Verde, I.; Bielenberg, D.G. A genome-wide analysis of MADS-box genes in peach [Prunus persica (L.) Batsch]. BMC Plant Biol. 2015, 15, 41. [CrossRef]

58. Shu, Y.; Yu, D.; Wang, D.; Guo, D.; Guo, C. Genome-wide survey and expression analysis of the MADS-box gene family in soybean. Mol. Biol. Rep. 2013, 40, 3901-3911. [CrossRef]

59. Tian, Y.; Dong, Q.; Ji, Z.; Chi, F.; Zhou, Z. Genome-wide identification and analysis of the MADS-box gene family in apple. Gene 2014, 555, 277-290. [CrossRef]

60. Bai, G.; Yang, D.; Cao, P.; Yao, H.; Zhang, Y.; Chen, X.; Xiao, B.; Li, F.; Wang, Z.; Yang, J. Genome-wide identification, gene structure and expression analysis of the MADS-Box gene family indicate their function in the development of tobacco (Nicotiana tabacum L.). Int. J. Mol. Sci. 2019, 20, 5043. [CrossRef]

61. Schilling, S.; Kennedy, A.; Pan, S.; Jermiin, L.S.; Melzer, R. Genome-wide analysis of MIKC-type MADS-box genes in wheat: pervasive duplications, functional conservation and putative neofunctionalization. New Phytol. 2020, 225, 511-529. [CrossRef]

62. Xu, Y.; Ding, Z.; Yao, Y.; Gong, R.; Wen, Y. Karyotype analysis of four pomegranate cultivars. Nonwood For. Res. 2008, 26, 47-52.

63. De Bodt, S.; Raes, J.; De Peer, Y.V.; Theisen, G. And then there were many: MADS goes genomic. Trends Plant Sci. 2003, 8, 475-483. [CrossRef]

64. Tang, W.; Tu, Y.; Cheng, X.; Zhang, L.; Meng, H.; Zhao, X.; Zhang, W.; He, B. Genome-wide identification and expression profile of the MADS-box gene family in Erigeron breviscapus. PLoS ONE 2019, 14, e0226599. [CrossRef]

65. Riechmann, J.L.; Heard, J.E.; Martin, G.M.; Reuber, L.; Jiang, C.; Keddie, J.; Adam, L.; Pineda, O.; Ratcliffe, O.; Samaha, R. Arabidopsis transcription factors: genome-wide comparative analysis among eukaryotes. Science 2000, 290, 2105-2110. [CrossRef]

66. Zhang, Y.; Tang, D.; Lin, X.; Ding, M.; Tong, Z. Genome-wide identification of MADS-box family genes in moso bamboo (Phyllostachys edulis) and a functional analysis of PeMADS5 in flowering. BMC Plant Biol. 2018, 18, 176. [CrossRef]

67. Cui, M.; Wang, C.; Wu, W.; Wang, J.; Tang, W.; Zhang, W.; Zhu, X.; Jia, H.; Shen, W.; Fang, J. Expression characteristic analysis of MADS-box family members of grape transcription factors in berry development and ripening process. J. Fruit Sci. 2017, 34, 1497-1508.

68. Hundertmark, M.; Hincha, D.K. LEA (Late Embryogenesis Abundant) proteins and their encoding genes in Arabidopsis thaliana. BMC Genom. 2008, 9, 118. [CrossRef] [PubMed]

69. Li, P.C.; Yu, S.W.; Shen, J.; Li, Q.Q.; Li, D.P.; Li, D.Q.; Zheng, C.C.; Shu, H.R. The transcriptional response of apple alcohol acyltransferase (MdAAT2) to salicylic acid and ethylene is mediated through two apple MYB TFs in transgenic tobacco. Plant Mol. Biol. 2014, 85, 627-638. [CrossRef] [PubMed] 
70. Kaufmann, K.; Melzer, R.; Theissen, G. MIKC-type MADS-domain proteins: Structural modularity, protein interactions and network evolution in land plants. Gene 2005, 347, 183-198. [CrossRef] [PubMed]

71. Ma, H.; Depamphilis, C.W. The ABCs of floral evolution. Cell 2000, 101, 5-8. [CrossRef]

72. Yoo, S.K.; Wu, X.; Lee, J.S.; Ji, H.A. AGAMOUS-LIKE 6 is a floral promoter that negatively regulates the FLC/MAF clade genes and positively regulates FT in Arabidopsis. Plant J. 2011, 65, 62-76. [CrossRef]

73. Ferrandiz, C.; Liljegren, S.J.; Yanofsky, M.F. Negative Regulation of the SHATTERPROOF Genes by FRUITFULL during Arabidopsis fruit development. Science 2000, 289, 436-438. [CrossRef]

74. Pinyopich, A.; Ditta, G.S.; Savidge, B.; Liljegren, S.J.; Baumann, E.; Wisman, E.; Yanofsky, M.F. Assessing the redundancy of MADS-box genes during carpel and ovule development. Nature 2003, 424, 85-88. [CrossRef] [PubMed]

75. Seymour, G.B.; Ryder, C.D.; Cevik, V.; Hammond, J.P.; Popovich, A.; King, G.J.W.; Vrebalov, J.; Giovannoni, J.J.; Manning, K. A SEPALLATA gene is involved in the development and ripening of strawberry (Fragaria x ananassa Duch.) fruit, a non-climacteric tissue. J. Ex. Bot. 2011, 62, 1179-1188. [CrossRef] [PubMed]

76. Theißen, G. Development of floral organ identity: Stories from the MADS house. Curr. Opin. Plant Biol. 2001, 4, 75-85. [CrossRef]

(C) 2020 by the authors. Licensee MDPI, Basel, Switzerland. This article is an open access article distributed under the terms and conditions of the Creative Commons Attribution (CC BY) license (http://creativecommons.org/licenses/by/4.0/). 